ARTICLE

https://doi.org/10.1038/s41467-018-08257-9

\title{
Diverse manifestations of the mid-Pleistocene climate transition
}

\author{
Youbin Sun ${ }^{1,2}$, Qiuzhen Yin ${ }^{3}$, Michel Crucifix ${ }^{3}$, Steven C. Clemens (1) ${ }^{4}$, Pablo Araya-Melo ${ }^{3}$, Weiguo Liu ${ }^{1,2}$, \\ Xiaoke Qiang ${ }^{1,2}$, Qingsong Liu (i) ${ }^{5}$, Hui Zhao ${ }^{1}$, Lianji Liang ${ }^{6}$, Hongyun Chen7, Ying Li ${ }^{1}$, Li Zhang ${ }^{1,8}$, \\ Guocheng Dong ${ }^{1,8}$, Ming Li1, Weijian Zhou ${ }^{1,2,9}$, Andre Berger ${ }^{3}$ \& Zhisheng An $n^{1,2,10}$
}

The mid-Pleistocene transition (MPT) is widely recognized as a shift in paleoclimatic periodicity from 41- to 100-kyr cycles, which largely reflects integrated changes in global ice volume, sea level, and ocean temperature from the marine realm. However, much less is known about monsoon-induced terrestrial vegetation change across the MPT. Here, on the basis of a 1.7-million-year $\delta^{13} \mathrm{C}$ record of loess carbonates from the Chinese Loess Plateau, we document a unique MPT reflecting terrestrial vegetation changes from a dominant 23-kyr periodicity before $1.2 \mathrm{Ma}$ to combined 100,41, and 23-kyr cycles after $0.7 \mathrm{Ma}$, very different from the conventional MPT characteristics. Model simulations further reveal that the MPT transition likely reflects decreased sensitivity of monsoonal hydroclimate to insolation forcing as the Northern Hemisphere became increasingly glaciated through the MPT. Our proxy-model comparison suggests varied responses of temperature and precipitation to astronomical forcing under different ice $/ \mathrm{CO}_{2}$ boundary conditions, which greatly improves our understanding of monsoon variability and dynamics from the natural past to the anthropogenic future.

\footnotetext{
${ }^{1}$ State Key Laboratory of Loess and Quaternary Geology, Institute of Earth Environment, Chinese Academy of Sciences, 710061 Xian, China. ${ }^{2}$ CAS Center for Excellence in Quaternary Science and Global Change, Chinese Academy of Sciences, 710061 Xian, China. ${ }^{3}$ Georges Lemaitre Center for Earth and Climate Research, Earth and Life Institute, Université Catholique de Louvain, 1348 Louvain-la-Neuve, Belgium. ${ }^{4}$ Department of Earth, Environmental and Planetary Sciences, Brown University, Providence 02912-1846 RI, USA. ${ }^{5}$ Centre for Marine Magnetism, Department of Ocean Science and Engineering, Southern University of Science and Technology, 518055 Shenzhen, China. ${ }^{6}$ College of Architecture and Civil Engineering, Beijing University of Technology, 100022 Beijing, China. ${ }^{7}$ The Institute of Hydrogeology and Environmental Geology, Chinese Academy of Geological Sciences, 050061 Shijiazhuang, China. ${ }^{8}$ Shaanxi Key Laboratory of Accelerator Mass Spectrometry Technology and Application, 710061 Xian, China. ${ }^{9}$ Interdisciplinary Research Center of Earth Science Frontier, Beijing Normal University, 100875 Beijing, China. ${ }^{10}$ Open Studio for Oceanic-Continental Climate and Environment Changes, Pilot National Laboratory for Marine Science and Technology (Qingdao), 266200 Qingdao, China. Correspondence and requests for materials should be addressed to Y.S. (email: sunyb@ieecas.cn)
} 
T he Pleistocene climate is characterized by significant glacial-interglacial changes in high-latitude ice volume ${ }^{1-3}$, global ocean temperature ${ }^{4}$, sea level ${ }^{5}$, and monsoonal climate $^{6}$. All these variables inherently interacted to generate a remarkable transition of the ice-age cycles from 41-kyr to 100-kyr cycles between 1.2 and $0.7 \mathrm{Ma}$, called the mid-Pleistocene transition (MPT) $)^{2,7,8}$. The MPT might be triggered by a nonlinear response to astronomical forcing ${ }^{9}$ induced by a secular $\mathrm{CO}_{2}$ decrease and/or progressive regolith erosion ${ }^{10-12}$. This transition is particularly apparent in numerous proxy indicators that are sensitive to changing glacial boundary conditions $s^{3-6,11,13}$. At middle and low latitudes, however, the proxies of monsooninduced wind and hydroclimate changes in the Arabian Sea and East Asia display prominent precession cycles during the middleto-late Pleistocene ${ }^{14,15}$.

Simulations with different climate models show that global monsoon changes are sensitive to changes in insolation, $\mathrm{CO}_{2}$ concentration, and ice volume ${ }^{16-19}$. Synthesis of Chinese loess, paleolake, and speleothem records confirms that the Asian summer monsoon variation was induced by combined effects of astronomical, ice, and $\mathrm{CO}_{2}$ forcing ${ }^{20}$. However, the relative roles of the insolation and coupled ice/ $\mathrm{CO}_{2}$ changes in driving orbital-scale monsoon variability remain controversial due to the spatial divergence and complexity of the proxy sensitivity to precipitation and temperature changes ${ }^{14,15,19-22}$.

Here we present a centennial-resolution $\delta^{13} \mathrm{C}$ record of inorganic carbonate $\left(\delta^{13} \mathrm{C}_{\mathrm{IC}}\right)$ of a thick loess sequence from the northwestern Chinese Loess Plateau (CLP), a region sensitive to orbital-to-millennial-scale monsoon variability 22,23 . Magnetostratigraphy and pedostratigrahpy, together with burial dating, provide a reliable chronology of the loess-paleosol sequences accumulated over the past $\sim 1.7 \mathrm{Ma}$. Loess $\delta^{13} \mathrm{C}_{\mathrm{IC}}$, a sensitive monsoon proxy, offers novel insights into Pleistocene monsoon variability and dynamics. Unlike the conventional expression of the MPT, our results reveal a compelling transition of the dominant rhythm in coupled monsoon-vegetation system from 23-kyr to combined 23-, 41-, and 100-kyr cycles across the MPT.

\section{Results}

Setting and sampling. CLP climate is characterized by seasonal changes in temperature and precipitation. Summer is the warm and humid season due to the influence of the summer monsoon, which transports heat and water vapor from the low-latitude oceans. The summer precipitation from May to September contributes to the annual precipitation by $60-75 \%$ and results in strong pedogenesis of the loess-paleosol sequences. In contrast, winter is the cold and dry season associated with strong winter monsoon wind, which is linked to the Siberian-Mongolian highpressure system. The winter monsoon transports vast of dust particles from inland Asia to the downwind CLP. Therefore, Chinese loess, as a unique continental archive, can document multi-scale monsoon variability linked to past climate changes in both high- and low-latitude regions ${ }^{20-26}$.

The Jingyuan loess sequence (JY, $36.35^{\circ} \mathrm{N}, 104.6^{\circ} \mathrm{E}, 2,210 \mathrm{~m}$ above sea level) is located at the depositional center of modern dust storms on the northwestern CLP (Fig. 1). A 430-m core was retrieved from the highest terrace of the Yellow River near Jingyuan County. The JY core consists of a 427-m loess deposit underlain by a 3-m gravel layer. A 40-m outcrop was excavated nearby to collect parallel samples spanning the last interglacial-glacial cycle. Continuous U-channel and discrete cube samples were taken from the split cores for alternatingfield and thermal demagnetization measurements, respectively (Methods). Three quartz samples were chosen from the underlying gravel layer for ${ }^{26} \mathrm{Al} /{ }^{10} \mathrm{Be}$ burial dating (Supplementary Fig. 1). Powder samples were taken at $10-\mathrm{cm}$ intervals for magnetic susceptibility, grain size, and $\delta^{13} C_{\mathrm{IC}}$ analyses.

Magnetostratigrahy and pedostratigrahy. Magnetic measurements and demagnetization spectra indicate that the JY loess sediments contain dominantly coarse-grained domain magnetite, which records the primary detrital remanent magnetization (Supplementary Figs. 2 and 3). Paleomagnetic results reveal that the Brunhes/Matuyama (B/M) boundary is recorded at the $S_{7} / L_{8}$ boundary and the Jaramillo subchron is located within $\mathrm{S}_{10}-\mathrm{L}_{13}$

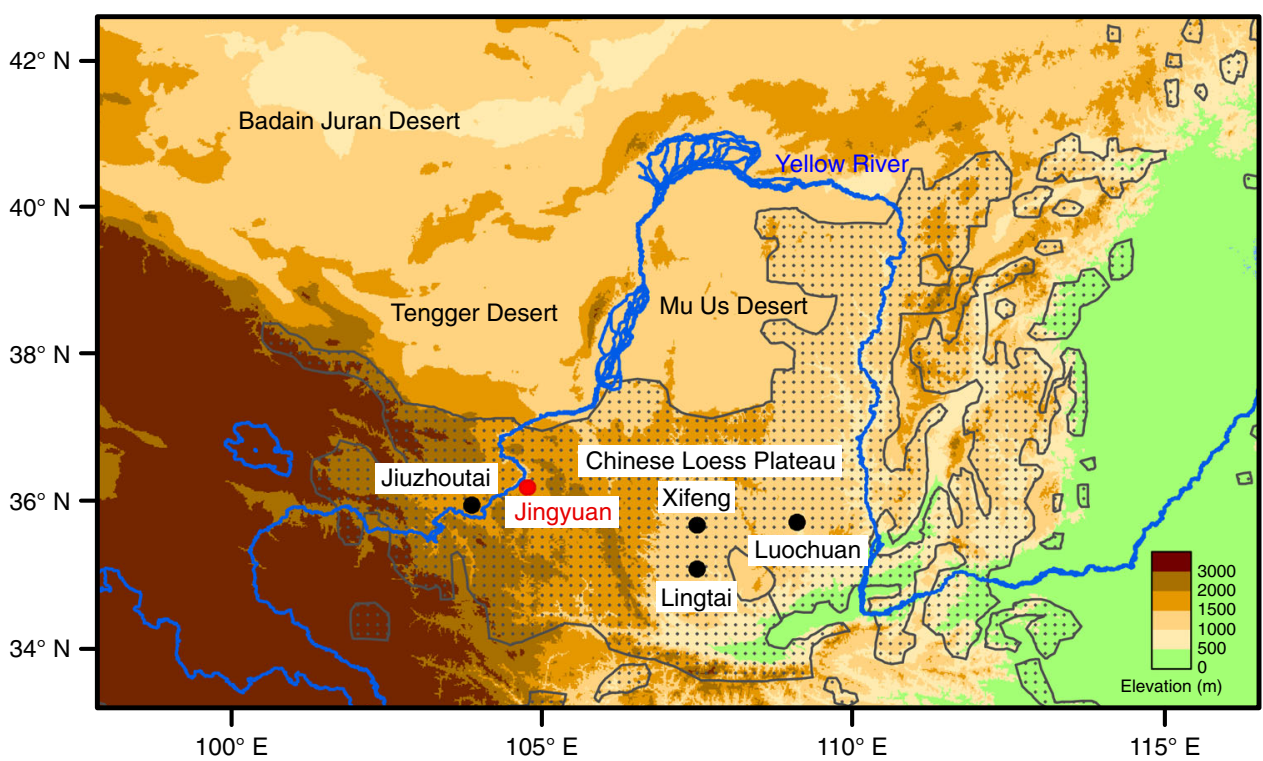

Fig. 1 Location of JY loess core and representative loess profiles on the Chinese Loess Plateau (CLP). Black dots denote four classic loess profiles, which

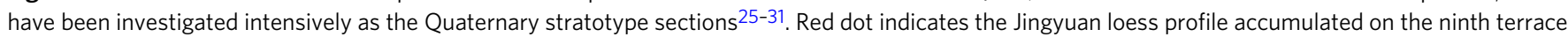
of the Yellow River in the northwestern CLP23,41 


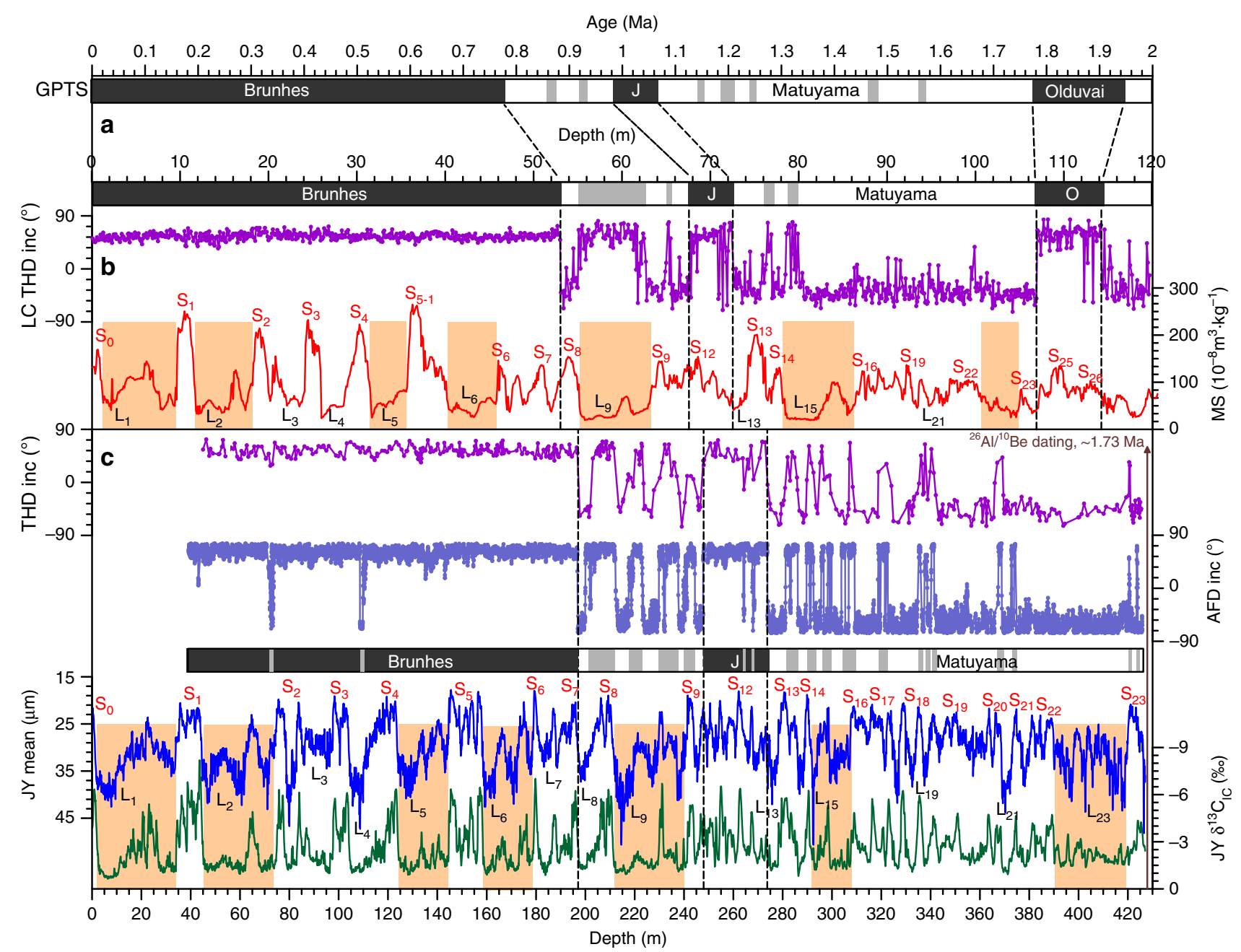

Fig. 2 Polarity and proxy variations of the JY loess sequence. a Geomagnetic polarity timescale (GPTS) ${ }^{32,33}$. b Magnetic susceptibility (MS) and magnetostratigraphy of Luochuan (LC) profile 27,31 . c JY $\delta^{13} C_{I C}$, mean, and magnetostratigrahy. The magnetostratigraphy is derived from inclination results measured by the alternating-field (AFD, light blue) and thermal (THD, purple) demagnetization methods. Dashed lines indicate the positions of paleomagnetic reversals (B/M Brunhes/Matuyama boundary, J Jaramillo, O Olduvai). Orange bars denote thick loess marker layers

(Fig. 2). The magnetostratigraphy of the JY loess sequence is well correlated with that of classic loess profiles from the central $\mathrm{CLP}^{27-31}$, e.g., the $\mathrm{B} / \mathrm{M}$ boundary at the top $\mathrm{L}_{8}$ and the Jaramillo subchron between $\mathrm{S}_{10}$ and $\mathrm{L}_{13}$ (Supplementary Fig. 4). Correlation of the JY magnetostratigrapy with geomagnetic polarity timescale ${ }^{32}$ indicates that the Olduvai subchron is not recorded at the JY section (Fig. 2).

In addition, several normal excursions are evident in the inclination results below the $\mathrm{B} / \mathrm{M}$ boundary, which either resulted from remagnetization of coarse-grained magnetic particles or are related to genuine geomagnetic excursions ${ }^{33,34}$. Previous studies have deliberately evaluated the fidelity of these relatively shortlived directional anomalies, which could indicate remagnetization caused by physical realignment of magnetic grains in wetter conditions ${ }^{35}$ or by viscous remanent magnetization overprinting on the coarse-grained eolian magnetic particles ${ }^{36}$. The general correspondences between these short-lived directional anomalies and the grain-size curve seems supporting the remagnetization mechanism.

Loess-paleosol alternations can be reliably recognized and correlated throughout the entire CLP using magnetic susceptibility and grain-size variations. While the pedogenesis inferred from the magnetic susceptibility is relatively weak at the JY loess sequence, mean grain-size and $\delta^{13} C_{I C}$ variations faithfully document the loess-paleosol alternations from $S_{23}$ to $S_{0}$ (Fig. 2), consistent with the pedostratigraphy of other typical Chinese loess profiles ${ }^{25-31}$ (Supplementary Fig. 4). Seven thick loess units $\left(\mathrm{L}_{1}, \mathrm{~L}_{2}, \mathrm{~L}_{5}, \mathrm{~L}_{6}, \mathrm{~L}_{9}, \mathrm{~L}_{15}\right.$, and $\left.\mathrm{L}_{23}\right)$ can be readily identified as marker layers for pedostratigrapic correlation. In between these marker layers, JY loess-paleosol alternations from $S_{23}$ to $S_{0}$ can be easily counted from the mean grain-size variations, which are quite similar to large-amplitude grain-size fluctuations of other representative loess profiles (Supplementary Fig. 4).

${ }^{26} \mathrm{Al} /{ }^{10} \mathrm{Be}$ burial dating. The concentrations of ${ }^{26} \mathrm{Al}$ and ${ }^{10} \mathrm{Be}$ in quartz were derived from the measured isotopic ratios (Methods). ${ }^{10} \mathrm{Be}$ value was adjusted to match the currently accepted value ${ }^{37}$, and the ${ }^{26} \mathrm{Al} /{ }^{27} \mathrm{Al}$ ratio was normalized to standards ${ }^{38}$. For the Jingyuan location (latitude $36.35^{\circ} \mathrm{N}$ and elevation $\left.2210 \mathrm{~m}\right)^{39}$, cosmogenic nuclide production rates were estimated to be 150.42 and 22.09 atoms per gram per year for ${ }^{26} \mathrm{Al}$ and ${ }^{10} \mathrm{Be}$, respectively. Burial ages were calculated by iteratively solving equations without considering the post-burial cosmogenic nuclide production $^{40}$. Burial ages of three samples from the same gravel layer vary from 1.62 to $1.87 \mathrm{Ma}$, with uncertainties of $0.14-0.47 \mathrm{Ma}$ (Table 1). The average age of basal gravel layer was estimated to be $1.73 \pm 0.13 \mathrm{Ma}$, which is consistent with the timing of Lanzhou 
loess sequence on the ninth terrace of the Yellow River ${ }^{41}$. Integrating the paleomagnetic results and the burial dates suggests that the JY loess sequence accumulated after $1.77 \mathrm{Ma}$.

Chronology. The loess chronology has been generated using both orbital tuning ${ }^{25,26}$ and a grain-size model ${ }^{24,42,43}$. These approaches result in almost identical ages of the loess/paleosol boundaries from $\mathrm{S}_{8}$ to $\mathrm{S}_{0}$, matching well with the timing of the glacial/ interglacial transitions of benthic $\delta^{18} \mathrm{O}$ stack $^{3}$. During early-tomiddle Pleistocene, orbital tuning can provide better constraints on the timing of the loess/paleosol boundaries compared to the grain-size age model approach due to the capacity for more time control points ${ }^{25,26}$. However, orbital tuning can involve obliquity and precession imprints in the age model and thus hamper our assessment of the periodicity changes across the MPT.

Owing to the strong similarity of loess-paleosol alternations between the Jingyuan core and other classic loess profiles, a pedostratigraphic age model can be developed using only 12 tie points to match 7 thick loess layers to the stacked grain-size time series $^{25,26}$ (Fig. 3). The age model was refined by interpolation between 12 time controls using the weighted grain-size model ${ }^{24}$. The basal age of the JY loess was estimated to be $\sim 1.73 \mathrm{Ma}$, and

Table 1 Cosmogenic nuclide concentrations and burial age

\begin{tabular}{|c|c|c|c|c|}
\hline Sample & $\begin{array}{l}{ }^{26} \mathrm{Al}\left(10^{5}\right. \\
\text { atoms } / \mathrm{g})\end{array}$ & $\begin{array}{l}{ }^{10} \mathrm{Be}\left(10^{5}\right. \\
\text { atoms } / \mathrm{g})\end{array}$ & ${ }^{26} \mathrm{Al} /{ }^{10} \mathrm{Be}$ & $\begin{array}{l}\text { Burial age } \\
\text { (Ma) }\end{array}$ \\
\hline JY-1 (sand) & $3.17 \pm 0.38$ & $1.02 \pm 0.17$ & $3.10 \pm 0.63$ & $1.62 \pm 0.47$ \\
\hline JY-2 (gravel) & $4.35 \pm 0.24$ & $1.45 \pm 0.05$ & 0.19 & $1.69 \pm 0.14$ \\
\hline JY-3 (sand) & $2.43 \pm 0.41$ & $0.88 \pm 0.04$ & $2.76 \pm 0.48$ & $1.87 \pm 0.40$ \\
\hline Average age & & & & $1.73 \pm 0.13$ \\
\hline
\end{tabular}

the sedimentation rate varies between 10 and $70 \mathrm{~cm} / \mathrm{kyr}$. The age model can be verified by a robust correlation of the Jingyuan grain-size variation with stacked loess grain-size 25,26 and benthic $\delta^{18} \mathrm{O}$ records $^{3}$ (Fig. 3).

Reliability of this age model can be further assessed from the raw depth spectra over three depth intervals (Fig. 4a). The cyclicity ratios $(27 \mathrm{~m} / 11.5 \mathrm{~m}=2.3$ and $11.5 \mathrm{~m} / 5.5 \mathrm{~m}=2.1)$ in the depth spectra are consistent with the orbital ratios $(100 \mathrm{kyr} / 41 \mathrm{kyr}=2.4$ and $41 \mathrm{kyr} / 21 \mathrm{kyr}=2.0)$. Notably, a $5.5-\mathrm{m}$ cycle is evident throughout the entire sequence and becomes dominant below $\mathrm{L}_{15}$. Applying a $5.5 \mathrm{~m}=21 \mathrm{kyr}$ relationship results in a pedostratigraphic correlation of the lower portion to $\mathrm{L}_{15}-\mathrm{S}_{23}$ and a basal age of $\sim 1.73 \mathrm{Ma}$. Based on a linear depth-time transformation, an intrinsic cyclicity shift is evident from 23-kyr below $\mathrm{L}_{15}(1.2-1.7 \mathrm{Ma})$ to $100-\mathrm{kyr}$ above $\mathrm{L}_{9}$ (0-0.9 Ma) (Fig. 4b).

Alternatively, applying a $5.5 \mathrm{~m}=41 \mathrm{kyr}$ relationship could result in a pedostratigraphic correlation of the lower portion to $\mathrm{L}_{15}-\mathrm{S}_{29}$ and a classic MPT from 41- to 100-kyr cycles (Methods and Supplementary Fig. 5). This would require significantly lower sedimentation rate below $\mathrm{L}_{15}(13.5 \mathrm{~cm} / \mathrm{kyr})$ relative to that of the upper portion $\left(25 \mathrm{~cm} / \mathrm{kyr}\right.$ above $\left.\mathrm{L}_{15}\right)$. Such a remarkable change in the sedimentation rate below and above $\mathrm{L}_{15}$ is inconsistent with linear age-depth relationships of classic loess profiles on the CLP (Supplementary Fig. 6). Moreover, the basal age ( 2.2 Ma) estimated from the alternative pedostratigraphic correlation is significantly older than independent paleomagnetic and burial dating results. Thus we consider that the alternative pedostratigraphic correlation is sedimentologically implausible.

Loess $\delta^{13} C_{I C}$ implication. Proxies related to vegetation change such as carbon isotopes of organic matter and inorganic carbonate in Chinese loess have been employed to assess coupled

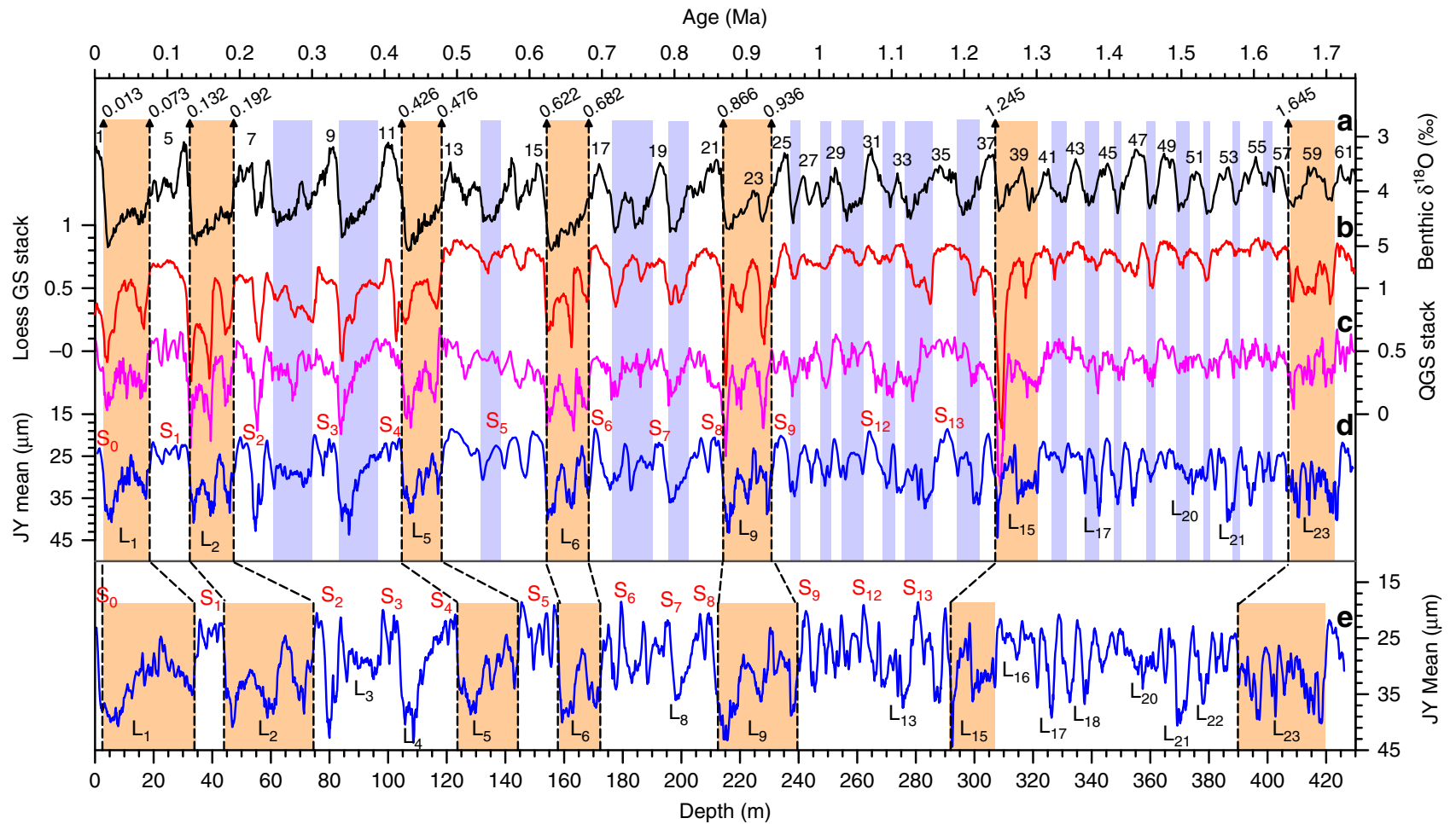

Fig. 3 Comparison of JY grain-size time series with stacked loess grain-size and benthic $\delta^{18} \mathrm{O}$. a Benthic $\delta^{18} \mathrm{O}$ stack $^{3}$. b Loess grain-size (GS) stack ${ }^{25}$. c Quartz grain-size (QGS) stack ${ }^{26}$. d JY mean grain-size on age scale. e JY mean grain-size on depth scale. Dashed lines denote that the chronology was generated by matching the timing of seven loess marker layers $\left(L_{1}, L_{2}, L_{5}, L_{6}, L_{9}, L_{15}\right.$, and $\left.L_{23}\right)$ to stacked grain-size time series. Orange and blue bars indicated the correlation of thick marker layers and other loess units to glacial stages 

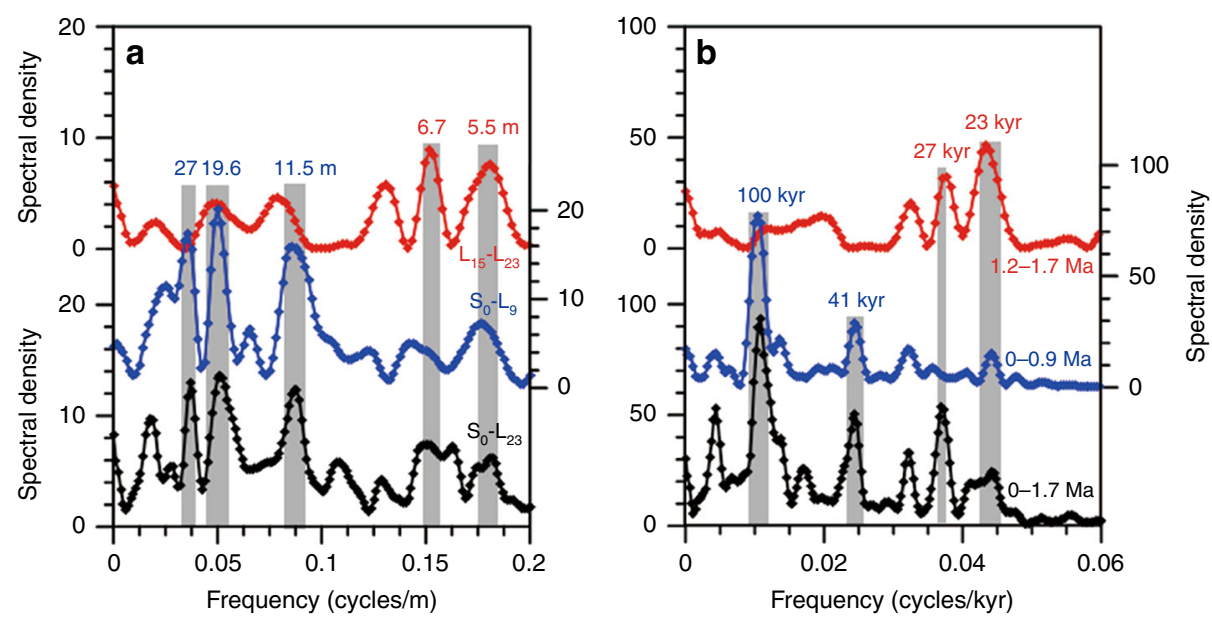

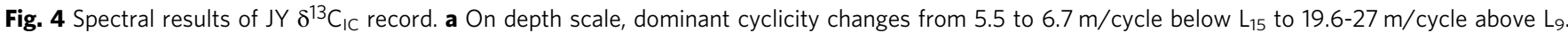
b The dominant cyclicity on age scale is evidently shifted from $23-\mathrm{kyr}$ before $1.2 \mathrm{Ma}$ (below $\mathrm{L}_{15}$ ) to 100 -kyr after $0.9 \mathrm{Ma}$ (above $\mathrm{L}_{9}$ )

monsoon-vegetation changes ${ }^{44-47}$. Both detrital and pedogenic carbonates are present in the Chinese loess deposits ${ }^{48,49}$. Carbon isotopes of the detrital carbonates from dust source areas over inland Asia vary between a narrow range of $-0.9 \%$ to $0.7 \%{ }^{22}$. Thus the carbon isotope of inorganic carbonate $\left(\delta^{13} \mathrm{C}_{\mathrm{IC}}\right)$ in Chinese loess is controlled mainly by two factors: carbon isotopes of pedogenic carbonate and the proportion of pedogenic carbonates $^{22,50}$. The vegetation in the western CLP is dominated by $\mathrm{C} 3$ plants and its carbon isotopes varied by $\sim 2-3 \%$ due to the biomass changes at glacial-interglacial timescales ${ }^{44,51,52}$. The carbon isotopic difference between inorganic carbonate and organic matter indicates that secondary carbonates roughly contribute two thirds of the glacial-interglacial $\delta^{13} \mathrm{C}_{\mathrm{IC}}$ fluctuations $(\sim 7 \%$ ) , which is also attributed to changing vegetation density ${ }^{22,44}$.

To determine the climate-vegetation linkage, the $\delta^{13} \mathrm{C}_{\mathrm{IC}}$ results of 20 surface soil samples over the CLP were compared with the precipitation and temperature data over 1981-2010 from the China meteorological data center (Supplementary Fig. 7). The correlation between the $\delta^{13} \mathrm{C}_{\mathrm{IC}}$ results and mean annual/summer precipitation is quite similar, whereas its correlation with the mean annual temperature is much higher than the mean summer temperature. Correlations between the $\delta^{13} \mathrm{C}_{\mathrm{IC}}$ of surface soil samples and climate variables reveal that while both mean annual temperature and precipitation can affect vegetation growth, mean annual summer precipitation likely plays a dominant role in the vegetation growth over the northwestern CLP. Since temperature and precipitation are strongly coupled over the CLP (i.e., warm-humid in summer and cold-dry in winter), loess $\delta^{13} \mathrm{C}_{\mathrm{IC}}$ can serve as a sensitive indicator of the monsoon-induced vegetation change during the Pleistocene.

The $\delta^{13} \mathrm{C}_{\mathrm{IC}}$ records display clear precession and millennial oscillations over the last $140 \mathrm{ka}$ (Fig. 5), identical to those in Chinese speleothem and Greenland ice-core records ${ }^{15,53}$. During marine isotope stage 5 (MIS 5), three negative peaks in the loess $\delta^{13} \mathrm{C}_{\mathrm{IC}}$ exhibit a decreasing trend from MIS $5 \mathrm{e}$ to MIS 5a, corresponding to changing summer insolation maxima. Our $\delta^{13} \mathrm{C}_{\mathrm{IC}}$ records also exhibit stadial-interstadial oscillations. Thirteen Heinrich-like events revealed by the loess ${ }^{13} \mathrm{C}_{\text {IC }}$ records match well with weak summer monsoon intervals in the speleothem $\delta^{18} \mathrm{O}$ and cold stadials in the Greenland ice core. High similarity between precession-to-millennial variability in Chinese loess, speleothem, and Greenland ice-core records confirms that our loess $\delta^{13} \mathrm{C}_{\mathrm{IC}}$ record is sensitive to both highlatitude temperature and low-latitude hydrological changes.
Sensitivity simulations. To estimate the monsoon sensitivity to various forcings, we use the set of 61 experiments with the climate model HadCM $3^{54}$, which were designed to sample the ensemble of glacial, $\mathrm{CO}_{2}$, and astronomical conditions experienced by the land-ocean-atmosphere system during the Pleistocene (Methods). A statistical model (called emulator) is used to interpolate the output of these experiments and to simulate the trajectory of the climate system throughout the Pleistocene. The model results are used to estimate the relative influences of different astronomical parameters (eccentricity, obliquity, and precession $)^{35}, \mathrm{CO}_{2}$ concentrations $(180-280 \mathrm{ppmv})^{56,57}$, and discrete levels of glaciation ranging from 1 (Holocene-like) to 11 (Last Glacial Maximum) 54 (Supplementary Fig. 8).

As the loess $\delta^{13} \mathrm{C}_{\mathrm{IC}}$ record is affected by changes in mean annual precipitation (MAP) and temperature (MAT), we focused on these two variables averaged over northern China $\left(30-40^{\circ} \mathrm{N}\right.$, $\left.104-120^{\circ} \mathrm{E}\right)$, where the precipitation change is more sensitive to summer monsoon intensity ${ }^{19}$. The sensitivity analysis was based on the emulator approach ${ }^{54}$. The emulator is evaluated using a leave-one-out cross-validation approach, which consists of predicting the output of one experiment using the emulator calibrated on all the other experiments. Prediction errors for the MAT and MAP over northern China are well calibrated, and about $2 / 3$ of the prediction errors are within one standard deviation (Supplementary Fig. 9).

The calibrated emulator is then used for two purposes. First, we estimated the evolution of these indices throughout the Pleistocene to reconstruct the MAP and MAT curves. The MAP and MAT values are the estimated equilibrium response of HadCM3 for forcing conditions spanning the last 1.7 Ma. The climate evolution estimated following this approach considers thus that MAT and MPT are in quasi-equilibrium with the forcing components, including astronomical solutions ${ }^{55}$, ice levels ${ }^{3}$, and $\mathrm{CO}_{2}$ concentrations ${ }^{56,57}$. Next, we estimated the total variances of both MPT and MAT with the emulator, before and after the MPT. The expected variances of these variables caused by the variations of only one or two factors (eccentricity and longitude of perihelion, obliquity, ice, and $\mathrm{CO}_{2}$ ) were estimated by assuming that the other factors are fixed ${ }^{54}$.

Mid-Pleistocene monsoon transition. The mean grain-size (an indicator of the winter monsoon intensity $\left.{ }^{25,26}\right)$ and $\delta^{13} \mathrm{C}_{\mathrm{IC}}(\mathrm{a}$ proxy of monsoon-induced vegetation density 22,44 ) records display remarkable changes in both frequency and amplitude 


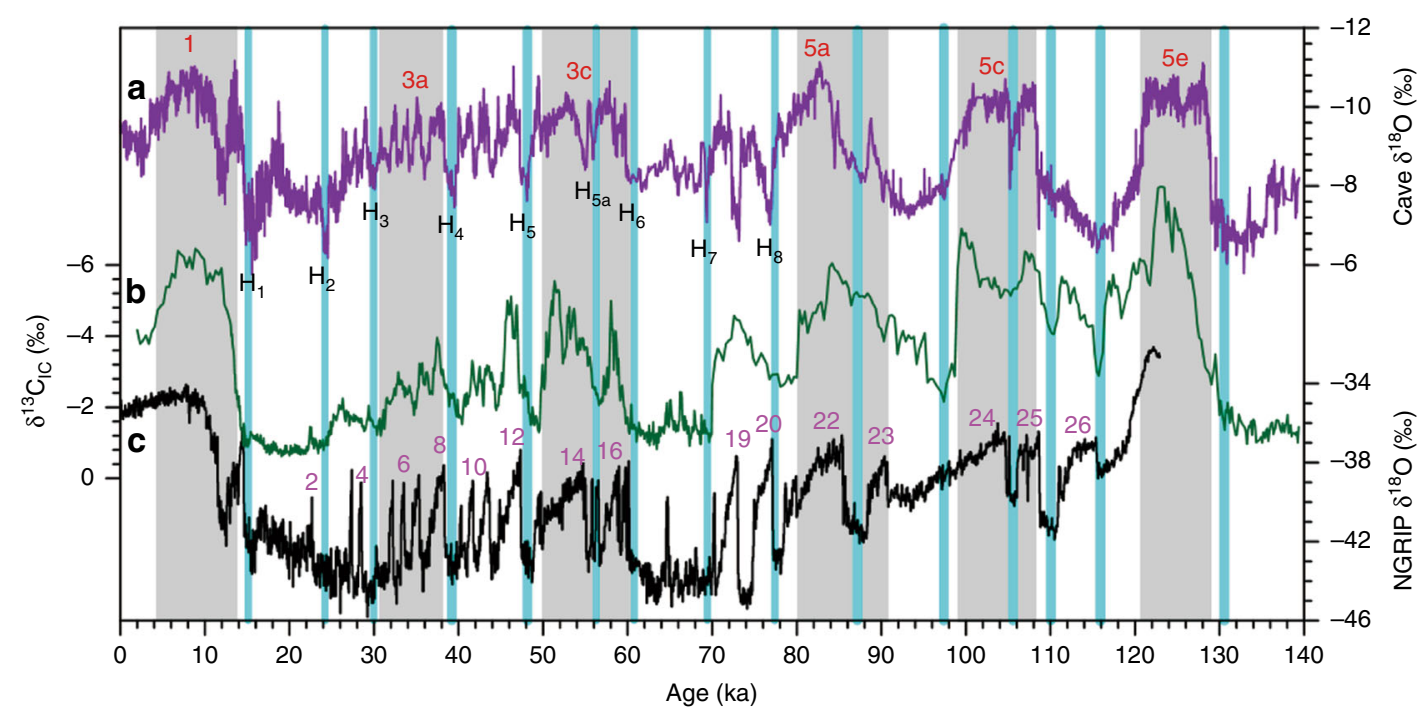

Fig. 5 Proxy variations over the last 140 ka from Greenland ice core, Chinese loess, and speleothem. a Chinese spleothem $\delta^{18} \mathrm{O}$ record ${ }^{15}$. b JY loess $\delta^{13} C_{\mathrm{IC}}$. c Greenland ice-core $\delta^{18} \mathrm{O}$ record ${ }^{53}$. Dashed lines denote correlations of positive loess $\delta^{13} \mathrm{C}_{\mathrm{IC}}$ and speleothem $\delta^{18} \mathrm{O}$ with low Greenland temperature

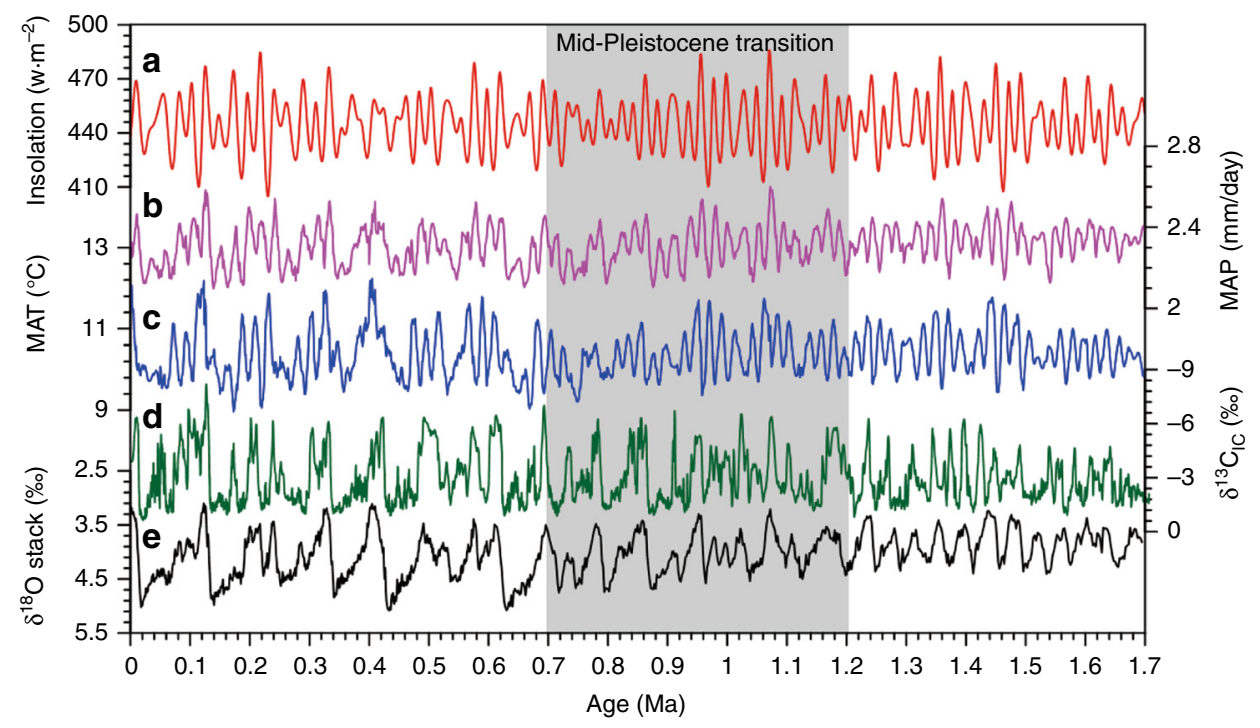

Fig. 6 Variations of proxy data and model results over the past $1.7 \mathrm{Ma}$. a Summer insolation at $65^{\circ} \mathrm{N}^{55}$. $\mathbf{b}$ Simulated mean annual precipitation (MAP) and c mean annual temperature (MAT) over the northern China. d JY loess $\delta^{13} C_{I C}$ record. e Benthic $\delta^{18} \mathrm{O}$ stack ${ }^{3}$. The gray bar denotes the mid-Pleistocene transition

around two coarsening loess units $\left(\mathrm{L}_{15}\right.$ and $\left.\mathrm{L}_{9}\right)$ (Fig. 2). Notably, the $\delta^{13} \mathrm{C}_{\mathrm{IC}}$ records show a distinctive transition from rapid oscillations (5.5 and $6.7 \mathrm{~m} /$ cycle) below $\mathrm{L}_{15}$ to low-frequency fluctuations $\left(11.5,19.6\right.$ and $27 \mathrm{~m} /$ cycle) above $\mathrm{L}_{9}$, representing an intrinsic shift from 23-kyr before 1.2 Ma to 41- and 100-kyr cycles after $0.9 \mathrm{Ma}$ (Fig. 4). Over longer timescales, the loess $\delta^{13} \mathrm{C}_{\mathrm{IC}}$ record exhibits distinctive glacial-interglacial and precessional variability over the past $1.7 \mathrm{Ma}$, which differs significantly from both summer insolation and benthic $\delta^{18} \mathrm{O}$ (Fig. 6). In the loess $\delta^{13} \mathrm{C}_{\mathrm{IC}}$ records, precessional cycles were dominant before 1.2 Ma, followed by a mixing of 23- and 41kyr cycles during the mid-Pleistocene. After 0.9 Ma, the 100-kyr glacial-interglacial cycles became dominant relative to the already present 41 - and 23-kyr periodicities. The durations and rhythms of the interglacial climate varied significantly across the MPT. The past eight interglacials (MIS 21-1) are characterized by reduced precession-band variance and long durations (30-60 kyr) compared to precession-dominated interglacials before the MPT.

The timing and duration of the MPT is well illustrated using continuous wavelet transforms (Methods and Fig. 7). Unlike the classical expression of a shift from 41 - to 100 -kyr cycles revealed by the benthic $\delta^{18} \mathrm{O}$ stack, our loess $\delta^{13} \mathrm{C}_{\mathrm{IC}}$ records document a diverse shift of the dominant periodicity from 23- to $100-\mathrm{kyr}$ cycles across the MPT. In the loess $\delta^{13} \mathrm{C}_{\mathrm{IC}}$ spectrum, the 23-kyr cycles were dominant before $1.2 \mathrm{Ma}$ and weakened after $0.7 \mathrm{Ma}$, in contrast to the persistent precession cycles in the summer insolation spectrum. Meanwhile, the $100-\mathrm{kyr}$ power initiated at 1.2 $\mathrm{Ma}$ and became dominant after $0.7 \mathrm{Ma}$. The benthic $\delta^{18} \mathrm{O}$ spectrum, however, shows that the dominant periodicity shifted from 41-kyr cycles before $1.2 \mathrm{Ma}$ to 100 -kyr cycles after $0.7 \mathrm{Ma}$. While the timing and duration of the MPT are similar between terrestrial and marine records, different transitions in the frequency domain point to unique mechanisms governing the 


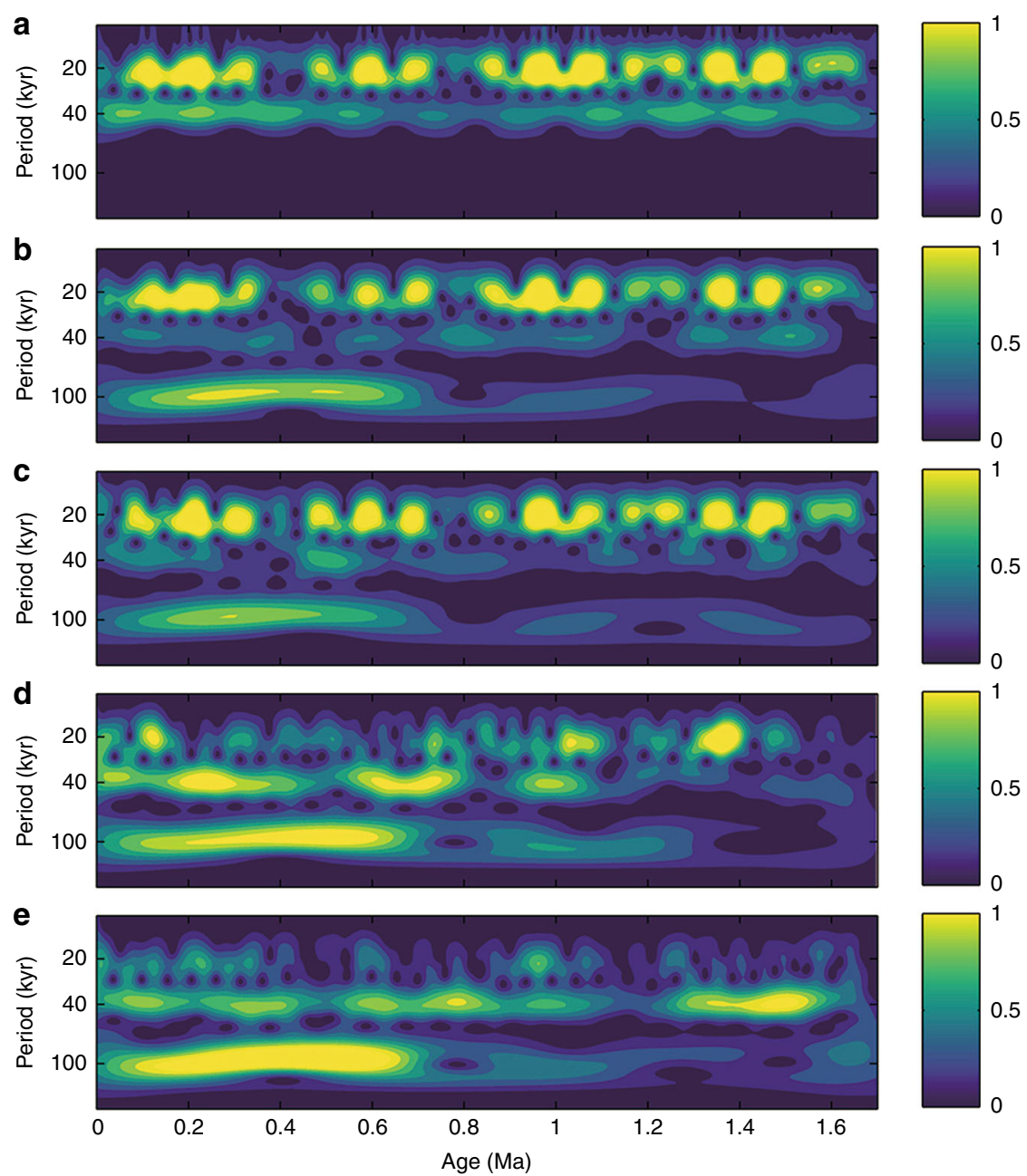

Fig. 7 Wavelet power spectra. a Summer insolation ${ }^{55}$, b simulated MAP, $\mathbf{c}$ simulated mean annual temperature, $\mathbf{d}$ loess $\delta^{13} C_{I C}$, and $\mathbf{e}$ benthic $\delta^{18} \mathrm{O}$ stack ${ }^{3}$

East Asian monsoon-vegetation responses to astronomical and coupled ice $/ \mathrm{CO}_{2}$ forcing.

\section{Discussion}

Astronomical parameters and lower boundary configurations are key factors affecting orbital-scale monsoon variability ${ }^{16-19}$. To test the plausible links of the monsoon-vegetation variability to changing insolation and ice sheets, we performed cross-wavelet analyses of the loess $\delta^{13} \mathrm{C}_{\mathrm{IC}}$ with summer insolation and the benthic $\delta^{18} \mathrm{O}$. Cross-wavelet spectra reveal that over the Pleistocene the 23- and 41-kyr cycles in the $\delta^{13} \mathrm{C}_{\mathrm{IC}}$ records show strong coherence with the precession and obliquity signals, while remarkable glacial-interglacial fluctuations at both the 100- and 41-kyr periodicities started to be highly coupled with the benthic $\delta^{18} \mathrm{O}$ stack after the MPT (Fig. 8). Different coherency of the loess $\delta^{13} \mathrm{C}_{\mathrm{IC}}$ with summer insolation and the benthic $\delta^{18} \mathrm{O}$ mainly in the 100-kyr band suggests that evolving glacial boundary conditions across the MPT may have diminished the climate sensitivity to astronomical forcing by placing strong ice/ $\mathrm{CO}_{2}$ constraints on the coupled monsoon-vegetation system.

The major differences of these forcing factors across the MPT are the ice extent and $\mathrm{CO}_{2}$ concentration during glacial maxima ${ }^{3,58}$. Thus sensitivity analyses were based on full glacial-interglacial ranges of the ice levels (1-11) and $\mathrm{CO}_{2}$ concentrations (180-280 ppmv) after the MPT and half ranges of the ice levels (1-6) and $\mathrm{CO}_{2}$ concentrations (220-280 ppmv) before the MPT. Sensitivity results indicate that the MAT is primarily determined by both precession and $\mathrm{CO}_{2}$, and to a lesser extent by ice, and the MAP is mainly driven by precession and less by ice and $\mathrm{CO}_{2}$ (Fig. 9). The coupled ice/ $\mathrm{CO}_{2}$ impact on the MAT is largely attributed to the $\mathrm{CO}_{2}$ change, whereas their impact on the MAP is a combination of both ice and $\mathrm{CO}_{2}$ changes. Most remarkable differences across the MPT are the decreased sensitivities of both the MAP and MAT to precession forcing and the increased sensitivities of only the MAT to the $\mathrm{CO}_{2}$ and coupled ice/ $\mathrm{CO}_{2}$ forcing. MAT is thus less sensitive to precession forcing after the MPT when the Northern Hemisphere was more glaciated.

Different sensitivities of the MAP and MAT changes to precession, ice, and $\mathrm{CO}_{2}$ forcing can lead to diverse manifestations in the amplitude and frequency domains across the MPT (Fig. 6). The simulated MAP over northern China during the last $1.7 \mathrm{Ma}$ shows a persistent 23-kyr periodicity, while the ice/ $\mathrm{CO}_{2}$ modulation on the MAP became distinctive during glacial periods after $0.9 \mathrm{Ma}$. By contrast, the simulated MAT change exhibits relatively warm interglacials during 1.5-0.9 Ma and an increase in glacial-interglacial amplitude after the mid-Brunhes event $(\sim 0.42$ $\mathrm{Ma})^{59}$. Wavelet spectra of the simulated MAP and MAT reveal a distinctive transition from a dominant 23-kyr periodicity before 1.2 Ma to combined 23- and 100-kyr cycles after 0.7 Ma (Fig. 7). Filtered 100- and 23-kyr components in these proxies confirm that the onset of the 100-kyr cycle across the MPT is evident in the loess $\delta^{13} \mathrm{C}_{\mathrm{IC}}$, and simulated MAT and MAP, while the 23-kyr 

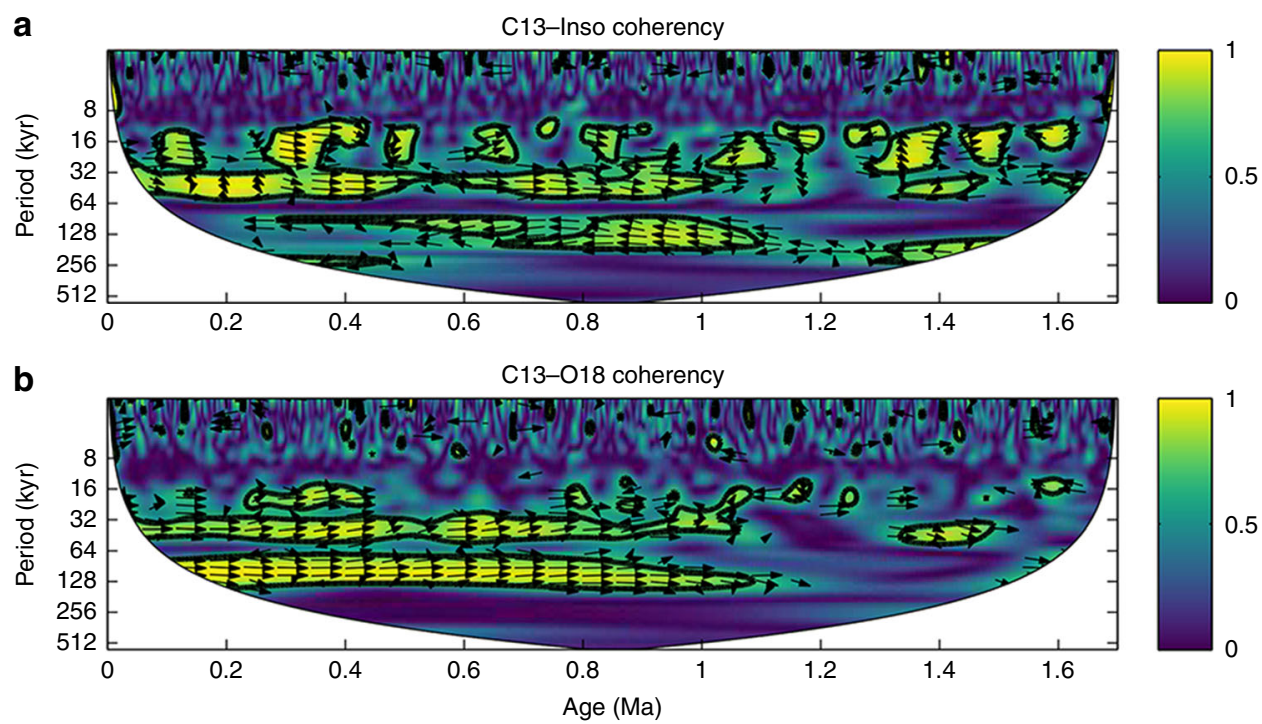

Fig. 8 Cross wavelet spectra. a JY loess $\delta^{13} C_{I C}$ vs. summer insolation ${ }^{55}$, b JY loess $\delta^{13} C_{I C}$ vs. benthic $\delta^{18} \mathrm{O}$ stack . Black contours indicate the coherence above $5 \%$ significance level
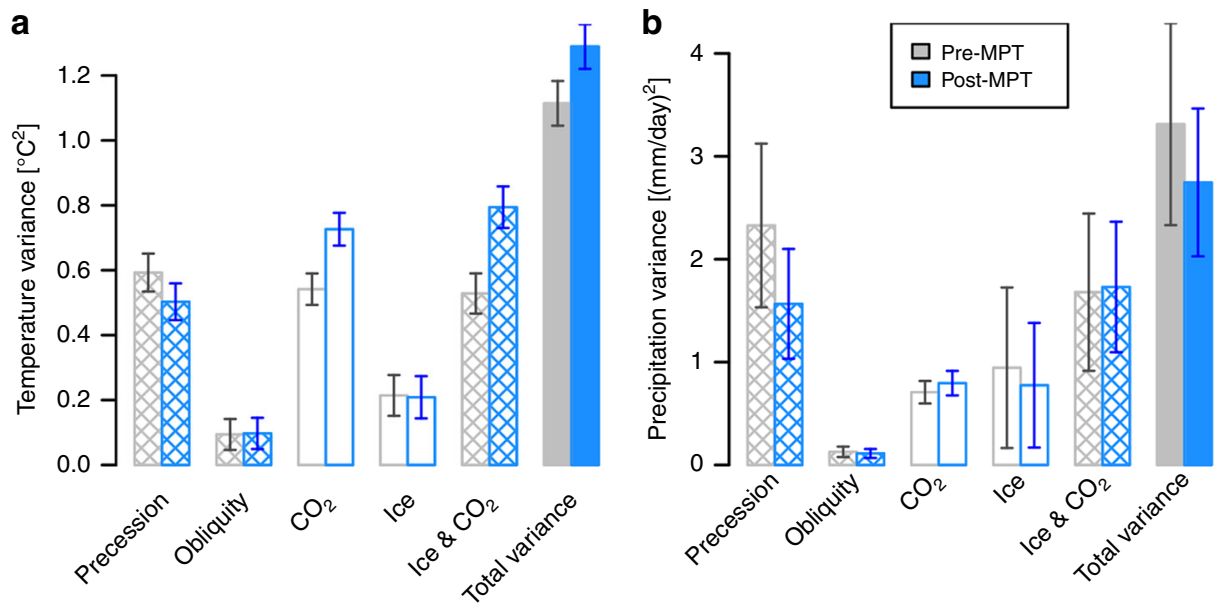

Fig. 9 Sensitivity of temperature and precipitation to astronomical, ice, and $\mathrm{CO}_{2}$ forcing. a Mean annual temperature (MAT) and $\mathbf{b}$ mean annual precipitation (MAP) responses to precession and obliquity, ice, $\mathrm{CO}_{2}$, and coupled ice $/ \mathrm{CO}_{2}$ forcing. Temperature and precipitation variances are spited into contributions for precession, obliquity, ice, $\mathrm{CO}_{2}$, and coupled ice and $\mathrm{CO}_{2}$ variation before the MPT (pre-MPT, gray) and after the MPT (post-MPT, blue), respectively. The combined ice $/ \mathrm{CO}_{2}$ contribution is not estimated by simply adding up the individual impacts of ice and $\mathrm{CO}_{2}$ because their effects can partly cancel out each other

cycle is less evident in the benthic $\delta^{18} \mathrm{O}$ than other three proxies (Supplementary Fig. 10). As the MAT and MAP are two important factors affecting the vegetation growth over the CLP, their frequency changes are imprinted in the $\delta^{13} \mathrm{C}_{\mathrm{IC}}$ record as a transition from the dominant 23-kyr to combined 23-, 41-, and 100 -kyr cycles across the mid-Pleistocene.

In summary, our loess $\delta^{13} C_{I C}$ time series, for the first time, illustrate a transition of coupled monsoon-vegetation changes from a dominant 23-kyr periodicity to the combined 23-, 41-, and $100-k y r$ cycles during the mid-Pleistocene, differing from the well-known MPT from 41- to $100-\mathrm{kyr}$ cycles in most marinebased proxy records. While the MPT was usually associated with an increase in ice volume denoted by addition of 41 - and 100 -kyr variances in the benthic $\delta^{18} \mathrm{O}$ record, sensitivity experiments indicate that the ice impacts on the MAT and MAP over northern China did not vary significantly across the MPT. Rather, the large-amplitude $100-\mathrm{kyr}$ cycle in loess $\delta^{13} \mathrm{C}_{\mathrm{IC}}$ is likely attributed to the amplified effect of glacial-interglacial $\mathrm{CO}_{2}$ changes on the MAT. Proxy-model comparison reveals that the monsoon-vegetation changes responded dominantly to astronomical forcing before the MPT when the ice and $\mathrm{CO}_{2}$ variability was relatively small. After the MPT, however, the precession forcing was attenuated by the coupled ice- $\mathrm{CO}_{2}$ effects. Our results highlight varied roles of insolation and coupled ice $/ \mathrm{CO}_{2}$ factors in driving the temperature and hydroclimate changes from the natural past to the anthropogenic future.

\section{Methods}

Drilling and sampling. In 2008, we drilled a 430-m core with a recovery rate of $98 \%$ at the highest tableland near Jingyuan County. The core consists of a $427-\mathrm{m}$ loess deposits underlain by $3-\mathrm{m}$ gravel layer. Since the recovery rate for the upper $40-\mathrm{m}$ is $<85 \%$, we investigated a nearby $40-\mathrm{m}$ outcrop to collect powder samples spanning the last interglacial-glacial cycle. Continuous U-channel samples were taken from the split core sections $(40-427 \mathrm{~m}$ ) for alternating-field magnetization (AFD) measurement. Discrete samples were also collected at $0.5-\mathrm{m}$ intervals using nonmagnetic quartz tubes for thermal demagnetization (THD) measurement. An upcore orientation mark was scribed on the U-channel and tube samples to provide a vertical reference. 
Magnetic measurements. Using a MFK1-FA Kappabridge equipped with a CS-3 high-temperature furnace, temperature-dependent susceptibility $(\kappa-T)$ curves were measured in an argon atmosphere from room temperature up to $700{ }^{\circ} \mathrm{C}$ with a heating rate of $11^{\circ} \mathrm{C} / \mathrm{min}$ and then back to room temperature. Hysteresis loops and the first-order reversal curve diagrams were obtained using a MicroMag 3900 automated vibrating sample magnetometer in a maximum field of $1000 \mathrm{mT}$. Stepwise isothermal remanent magnetization acquisition and direct current demagnetization of saturation isothermal remanence was conducted on the same samples. Hysteresis parameters were calculated after subtracting paramagnetic contributions. A Day plot was used to estimate the domain state and grain size of the magnetic particles.

Stepwise thermal demagnetization was performed on the tube samples from room temperature up to $620-640^{\circ} \mathrm{C}$ using a Thermal Demagnetizer (ASC TD-48). The U-channel samples were subjected to progressive AFD at peak fields up to 90 at $2.5-10-\mathrm{mT}$ intervals. The natural remanence of the tube and U-channel samples was measured using a $2 \mathrm{G}$ Enterprises Model 755 cryogenic magnetometer in a magnetically shielded room $(<150 \mathrm{nT})$. Most samples exhibit a weak viscous overprint, which can be removed at the alternating field of $20 \mathrm{mT}$ or at thermal treatment with temperature $>300^{\circ} \mathrm{C}$. Principal component analysis, calculated with a least square linear fit, was performed on the demagnetization data. The characteristic remanent magnetization directions were determined by a leastsquare fitting of the THD results between 300 and $585^{\circ} \mathrm{C}$ and of the AFD between 20 and $90 \mathrm{mT}$, with a maximum angular deviation $<15^{\circ}$.

${ }^{26} \mathbf{A l} /{ }^{10} \mathrm{Be}$ burial dating. Several kilograms of quartz-bearing sediments were collected from the gravel layer underlying the Jingyuan loess sequence. The quartzose sand and gravel samples were selected for crushing and then the $0.25-0.50-\mathrm{mm}$ fractions were isolated for further purification. Carbonates were dissolved with $\mathrm{HCl}$ and magnetic minerals were removed using magnetic separation. The quartz fractions were then leached repeatedly in hot agitated 5\% HF/ $\mathrm{HNO}_{3}$ overnight. The purified quartz fraction was dissolved in $5: 1 \mathrm{HF} / \mathrm{HNO}_{3}$ and spiked with $\sim 0.3 \mathrm{mg}{ }^{9} \mathrm{Be}$. An aliquot was taken for determining the aluminum content using inductively coupled plasma-atomic emission spectrometry. After evaporation and fuming of the remaining solution in $\mathrm{HClO}_{4}, \mathrm{Al}$ and Be were separated on ion-exchange columns in $0.4 \mathrm{M}$ oxalic acid, precipitated as hydroxides, and transformed to oxides in a furnace at $900{ }^{\circ} \mathrm{C}$. BeO was mixed with niobium and $\mathrm{Al}_{2} \mathrm{O}_{3}$ with copper powder for ${ }^{10} \mathrm{Be} /{ }^{9} \mathrm{Be}$ and ${ }^{26} \mathrm{Al} /{ }^{27} \mathrm{Al}$ measurement by accelerator mass spectrometer at Xi'an AMS Center, Institute of Earth Environment, Chinese Academy of Sciences.

An alternative age model. A different age model applied to the JY loess-paleosol sequence would generate a shift similar to the classic MPT from 41-kyr to 100-kyr cycles. In this case, the duration of the lower portion (below $\mathrm{L}_{15}$ ) needs be extended from $480 \mathrm{kyr}$ (AGE1, 1.25-1.73 Ma) to $950 \mathrm{kyr}$ (AGE2, 1.25-2.2 Ma) (Supplementary Fig. 5). On the AGE1 model, the lower portion of the JY loess core is correlated to $\mathrm{L}_{15}-\mathrm{S}_{23}$, whereas on the AGE2 model, this portion is correlated to $\mathrm{L}_{15}-\mathrm{S}_{29}$. We prefer the first age model (AGE1) because of two reasons. First, the Olduvai subchron is not recorded in the Jingyuan loess sequence and thus the basal age should be $<1.77 \mathrm{Ma}$. Second, a remarkable shift of the sedimentation rate from 13.5 to $25 \mathrm{~cm} / \mathrm{kyr}$ around $\mathrm{L}_{15}$ based on the JY-AGE2 is significantly different from the relative stable sedimentation rates in several classic loess profiles since the Olduvai subchron (Supplementary Fig. 6). Such a two-fold increase of the sedimentation rate at this single site cannot be explained by either tectonic or climatic factors.

In addition, numerous geomorphologic and paleomagnetic investigations on the terrace sequences of the Yellow River indicate that the loess sequences $\left(\mathrm{S}_{0}-\mathrm{S}_{24}\right)$ accumulated on the oldest terrace are $<1.8 \mathrm{Ma}^{28,41}$ Based on the new terrace classification of the Yellow River ${ }^{41}$, Jingyuan loess sequences $\left(\mathrm{S}_{0}-\mathrm{S}_{23}\right)$ was accumulated on the ninth terrace, with a rough basal age of $1.7 \mathrm{Ma}$. While an alternative pedostratigraphic correlation of the lower portion below $\mathrm{L}_{15}$ can generate a classical MPT shift from 41-kyr to 100 -kyr cycles, the relatively old basal age $(\sim 2.2 \mathrm{Ma})$ and two-fold increase in the sedimentation rates around $\mathrm{L}_{15}$ are apparently inconsistent with independent dating results and with age-depth relationships of other classic loess profiles on the CLP, respectively. Thus we think that our preferred AGE1 is more reasonable, as inferred from the paleomagnetic and burial dating results.

Spectral and wavelet analyses. Spectral analysis was conducted using the Redfit 3.5 software ${ }^{60}$. Wavelet analyses of loess $\delta^{13} \mathrm{C}_{\mathrm{IC}}$, simulated MAT and MAT, benthic $\delta^{18} \mathrm{O}^{3}$, and summer insolation ${ }^{55}$ were performed using MATLAB codes ${ }^{61}$ and a Morlet software package ${ }^{62}$. In order to visualize amplitude and frequency modulations, these data sets, except for the summer insolation, were preprocessed to isolate the 100-, 41-, and 21-kyr components using band-passing filters with central frequencies of $0.001,0.025$, and $0.05 / \mathrm{kyr}$ and bandwidths of $0.0002,0.005$, and $0.01 / \mathrm{kyr}$ before performing the wavelet transforms. The filtered signals are concentrated at three primary astronomical bands and then summed up for wavelet transforms. This preprocessing procedure can reduce the contribution of nonastronomical frequencies in the input signals and therefore improve the calculated power of three astronomical components in the paleoclimatic time series. Wavelet transform coherence was analyzed to assess high-amplitude responses of the loess $\delta^{13} \mathrm{C}_{\mathrm{IC}}$, benthic $\delta^{18} \mathrm{O}$ and summer insolation at three orbital bands.

Sensitivity experiments. We use 61 sensitivity experiments designed to sample efficiently changes in the astronomical configurations, $\mathrm{CO}_{2}$ concentrations, and Northern Hemisphere glaciations experienced during the Pleistocene ${ }^{54}$ (Supplementary Fig. 8). Each experiment is 300 -year long and we retained averages over the last 100 years for subsequent analysis. The level of Northern Hemisphere glaciations is represented by one variable called "glaciation index," and which refers to the 1 of the 11 stages of increasing glaciation sampled from the past glacial-interglacial cycle ${ }^{63}$. Level 1 is the Holocene, and level 11 is the Last Glacial Maximum. We note that the configuration choice is such that ice extent grows mainly between stages 1 and 3, while ice thickness growth mainly between levels 3 and 11 . Hence, by applying this design to represent ice volume changes during the early Pleistocene, we formulate the hypothesis that area fluctuations of ice sheets before the MPT were similar to after the MPT, but their thickness was smaller.

The sensitivity of the monsoon climate to the full spectrum of climatic conditions experienced during the Pleistocene is estimated using the climate model HadCM $3^{64}$. The atmospheric component dynamics are resolved on a $3.75^{\circ} \times 2.5^{\circ}$ longitude-latitude grid, and the oceanic component has a horizontal resolution of $1.25^{\circ} \times 1.25^{\circ}$. The HadCM3 has been shown to capture well enough the monsoon-ENSO interaction ${ }^{65}$ and natural variability of the summer rainfall over China ${ }^{66}$. Compared to observations, the summer subtropical anticyclone in HadCM3 is too strong as in many other models. This circulation anomaly tends to induce much rainfall over the maritime continent, but the error in North China turns out to be very small $(<1 \mathrm{~mm} /$ day $)$ and thus quite acceptable for our purpose.

In order to generate a forcing-response scenario over the Pleistocene, we scaled the benthic $\delta^{18} \mathrm{O}$ stack $^{3}$ to estimate the glaciation index over the last $1.7 \mathrm{Myr} . \mathrm{CO}_{2}$ concentration over the past $0.8 \mathrm{Ma}$ is obtained from Antarctic records ${ }^{56,57}$. The $\mathrm{CO}_{2}$ before the $0.8 \mathrm{Ma}$ was extrapolated to follow a linear relationship between ice volume and $\mathrm{CO}_{2}$ concentrations over the past eight glacial cycles (Supplementary Fig. 8). The MAP and MAT values are the estimated equilibrium responses of HadCM3 for forcing conditions spanning the last $1.7 \mathrm{Ma}$ by steps of $1 \mathrm{kyr}$. Validation for the MAT and MAP over northern China suggests that temperature is overall easier to predict than precipitation changes (Supplementary Fig. 9). Indeed, the annual precipitation response results from partly compensating trends in winter and summer. Annual changes are therefore smaller than seasonal changes and more difficult to detect over the internal model variability background. Error bars on the variances of the MAT and MAP correspond to the error variance of the emulator estimates. They combine internal model variability, which affects the values of the 100-year long averages used to calibrate the emulator. Uncertainty might come from the fact that we only have a limited number of experiments to map the sensitivity of HadCM3 to continuous changes in input variables.

\section{Data availability}

All relevant data that support the findings of this research are available from the corresponding author on request.

Received: 1 June 2018 Accepted: 20 December 2018

Published online: 21 January 2019

\section{References}

1. Hays, J. D., Imbrie, J. \& Shackleton, N. J. Variations in the Earth's orbit: pacemaker of the ice ages. Science 194, 1121-1132 (1976).

2. Ruddiman, W., Raymo, M., Martinson, D., Clement, B. \& Backman, J. Pleistocene evolution: Northern Hemisphere ice sheets and North Atlantic Ocean. Paleoceanography 4, 353-412 (1989).

3. Lisiecki, L. \& Raymo, M. A Pliocene-Pleistocene stack of 57 globally distributed benthic $\delta^{18} \mathrm{O}$ records. Paleoceanography 20, PA1003 (2005).

4. Herbert, T. D., Peterson, L. C., Lawrence, K. \& Liu, Z. H. Tropical Ocean temperatures over the past 3.5 million years. Science 328, 1530-1534 (2010).

5. Rohling, E. J. et al. Sea-level and deep-sea-temperature variability over the past 5.3 million years. Nature 508, 477-482 (2014)

6. deMenocal, P. B. Plio-Pleistocene African climate. Science 270, 53-59 (1995).

7. Pisias, N. G. Jr. \& Moore, T. C. The evolution of the Pleistocene climate: a time series approach. Earth Planet. Sci. Lett. 52, 450-458 (1981).

8. Raymo, M. E., Oppo, D. W. \& Curry, W. B. The mid-Pleistocene climate transition: a deep sea carbon perspective. Paleoceanography 12, 546-559 (1997).

9. Imbrie, J. et al. On the structure and origin of major glaciation cycles: 2. The 100,000 year cycle. Paleoceanography 8, 699-735 (1993).

10. Berger, A., Li, X. S. \& Loutre, M. F. Modelling northern hemisphere ice volume over the last 3 Ma. Quat. Sci. Rev. 18, 1-11 (1999).

11. Clark, P. et al. The middle Pleistocene transition: characteristics, mechanisms, and implications for long-term changes in atmospheric $\mathrm{pCO}_{2}$. Quat. Sci. Rev. 25, 3150-3184 (2006) 
12. Ganopolski, A. \& Calov, R. The role of astronomical forcing, carbon dioxide and regolith in 100 kyr glacial cycles. Clim. Past 7, 1415-1425 (2011).

13. Raymo, M. E., Lisiecki, L. E. \& Nisancioglu, K. H. Plio-Pleistocene ice volume, Antarctic climate, and the global $\delta^{18} \mathrm{O}$ record. Science 313, 492-495 (2006).

14. Clemens, S. C., Prell, W. L. \& Sun., Y. B. Astronomical-scale timing and mechanisms driving Late Pleistocene Indo-Asian Summer monsoons: reinterpreting cave speleothem $\delta^{18} \mathrm{O}$. Paleoceanography 25, PA4207 (2010).

15. Cheng, H. et al. The Asian monsoon over the past 640,000 years and ice age terminations. Nature 534, 640-646 (2016)

16. Prell, W. L. \& Kutzbach, J. E. Sensitivity of the Indian monsoon to forcing parameters and implications for its evolution. Nature 360, 647-652 (1992).

17. deMenocal, P. B. \& Rind, D. Sensitivity of Asian and African climate to variations in seasonal insolation, glacial ice cover, sea surface temperature, and Asian orography. J. Geophys. Res. 98, 7265-7287 (1993).

18. Yin, Q. Z. \& Berger, A. Individual contribution of insolation and $\mathrm{CO}_{2}$ to the interglacial climates of the past 800,000 years. Clim. Dyn. 38, 709-724 (2012).

19. Liu, Z. Y. et al. Chinese cave records and the East Asia summer monsoon. Quat. Sci. Rev. 83, 115-128 (2014).

20. An, Z. S. et al. Global monsoon dynamics and climate change. Annu. Rev. Earth Planet. Sci. 43, 2.1-2.49 (2015)

21. Clemens, S. C. et al. Precession-band variance missing from East Asian monsoon runoff. Nat. Commun. 9, 3364 (2018).

22. Sun, Y. B. et al. Astronomical and glacial forcing of East Asian summer monsoon variability. Quat. Sci. Rev. 115, 132-142 (2015).

23. Sun, Y. B. et al. Influence of Atlantic meridional overturning circulation on the East Asian winter monsoon. Nat. Geosci. 5, 46-49 (2012).

24. Porter, S. C. \& An, Z. S. Correlation between climate events in the North Atlantic and China during last glaciation. Nature 375, 305-308 (1995).

25. Ding, Z. L. et al. Stacked 2.6-Ma grain size record form the Chinese loess based on five sections and correlation with the deep-sea $\delta^{18} \mathrm{O}$ record. Paleoceanography 17, 5-1 (2002).

26. Sun, Y. B., Clemens, S. C., An, Z. S. \& Yu, Z. W. Astronomical timescale and palaeoclimatic implication of stacked 3.6-Myr monsoon records from the Chinese Loess Plateau. Quat. Sci. Rev. 25, 33-48 (2006).

27. Heller, F. \& Liu, T. S. Magnetostratigraphical dating of loess deposits in China. Nature 300, 431-433 (1982)

28. Burbank, D. W. \& Li, J. Age and palaeoclimatic significance of the loess of Lanzhou, north China. Nature 316, 429-431 (1985).

29. Kukla, G. et al. Pleistocene climates in China dated by magnetic susceptibility. Geology 16, 811-814 (1988).

30. Sun, D. H., Shaw, J., An, Z. S., Chen, M. Y. \& Yue, L. P. Magnetostratigraphy paleoclamtic interpretation of a continuous 7.2 Ma late Cenozoic from the Chinese Loess Plateau. Geophys. Res. Lett. 25, 85-88 (1998).

31. Liu, W. M., Zhang, L. Y. \& Sun, J. M. High resolution magnetostratigraphy of the Luochuan loess-paleosol sequence in the central Chinese Loess Plateau. Chin. J. Geophis. 53, 888-894 (2010).

32. Cande, S. C. \& Kent, D. V. Revised calibration of the geomagnetic polarity time scales for the late Cretaceous and Cenozoic. J. Geophys. Res. 100, 6093-6095 (1995).

33. Channell, J. E. T., Mazaud, A., Sullivan, P., Turner, S. \& Raymo, M. E. Geomagnetic excursions and paleointensities in the $0.9-2.15 \mathrm{Ma}$ interval of the Matuyama Chron at ODP site 983 and 984 (Iceland Basin). J. Geophys. Res. 107, B6 (2002).

34. Liu, Q. S. et al. Magnetostratigraphy of Chinese loess-paleosol sequences. Earth Sci. Rev. 150, 139-167 (2015).

35. Wang, X. S. et al. Remagnetization of quaternary eolian deposits: a case study from SE Chinese Loess Plateau. Geochem. Geophys. Geosyst. 6, Q06H18 (2005).

36. Jin, C. S. \& Liu, Q. S. Revisiting the stratigraphic position of the Matuyama-Brunhes geomagnetic polarity boundary in Chinese loess. Palaeogeogr. Palaeoclimatol. Palaeoecol. 299, 309-317 (2011).

37. Nishiizumi, K. et al. Absolute calibration of ${ }^{10} \mathrm{Be}$ AMS standards. Nucl. Instrum. Methods B 258, 403-413 (2007).

38. Nishiizumi, K. Preparation of ${ }^{26} \mathrm{Al}$ AMS standards. Nucl. Instrum. Methods B 223, 388-392 (2004).

39. Lal, D. Cosmic ray labeling of erosion surfaces: in situ nuclide production rates and erosion models. Earth Planet. Sci. Lett. 104, 424-439 (1991).

40. Granger, D. E. et al. New cosmogenic burial ages for Sterkfontein Member 2 Australopithecus and Member 5 Oldowa. Nature 522, 85-88 (2015).

41. Li, J. J. et al. Late Miocene-Quaternary rapid stepwise uplift of the NE Tibetan Plateau and its effects on climatic and environmental changes. Quat. Res. 81, 400-423 (2014).

42. Vandenberghe, J., An, Z. S., Nugteren, G., Lu, H. Y. \& Huissteden, K. V. New absolute time scale for the Quaternary climate in the Chinese loess region by grain-size analysis. Geology 25, 35-38 (1997).

43. Hao, Q. Z. et al. Delayed build-up of Arctic ice sheets during 400,000-year minima in insolation variability. Nature 490, 392-396 (2012).
44. Liu, W. G., Yang, H., Sun, Y. B. \& Wang, X. L. $\delta^{13} \mathrm{C}$ values of loess total carbonate: a sensitive proxy for Asian summer monsoon in arid northwestern margin of the Chinese Loess Plateau. Chem. Geol. 284, 317-322 (2011).

45. Ding, Z. L. \& Yang, S. L. C3/C4 vegetation evolution over the last $7.0 \mathrm{Myr}$ in the Chinese Loess Plateau: evidence from pedogenic carbonate $\delta^{13} \mathrm{C}$. Palaeogeogra. Palaeoecol. Palaeocl. 160, 291-299 (2000).

46. An, Z. S. et al. Multiple expansions of C4 plant biomass in East Asia since 7 Ma coupled with strengthened monsoon circulation. Geology 33, 705-708 (2005).

47. Yang, S. L. et al. Warming-induced northwestward migration of the East Asian monsoon rain belt from the Last Glacial Maximum to the midHolocene. Proc. Natl Acad. Sci. USA 112, 13178-13183 (2015).

48. Rao, Z. G., Zhu, Z. Y., Chen, F. H. \& Zhang, J. W. Does $\delta^{13} C_{\text {carb }}$ of the Chinese loess indicate past $\mathrm{C} 3 / \mathrm{C} 4$ abundance? A review of research on stable carbon isotopes of the Chinese loess. Quat. Sci. Rev. 25, 2251-2257 (2006).

49. Li, G. J., Chen, J. \& Chen, Y. Primary and secondary carbonate in Chinese loess discriminated by trace element composition. Geochim. Cosmochim. Acta 103, 26-35 (2013).

50. Ning, Y. F., Liu, W. G. \& An, Z. S. Variation of soil $\delta^{13} \mathrm{C}$ values in Xifeng loess-paleosol sequence and its paleoenvironmental implication. Chin. Sci. Bull. 51, 1350-1354 (2006).

51. Wang, G. A., Han, J. M. \& Liu, T. S. The carbon isotope composition of C3 herbaceous plants in loess area of northern China. Sci. China Earth Sci. 46, 1069-1076 (2003)

52. Rao, Z. G. et al. High-resolution summer precipitation variations in the western Chinese Loess Plateau during the last glacial. Sci. Rep. 3, 2785 (2013).

53. NGRIP members. High-resolution record of Northern Hemisphere climate extending into the last interglacial period. Nature 431, 147-151 (2004).

54. Araya Melo, P. A., Crucifix, M. \& Bounceur, N. Global sensitivity analysis of the Indian monsoon during the Pleistocene. Clim. Past 11, 45-61 (2015).

55. Berger, A. \& Loutre, M. F. Insolation values for the climate of the last 10 million years. Quat. Sci. Rev. 10, 297-317 (1991).

56. Luethi, D. et al. High-resolution carbon dioxide concentration record 650 00-800 000 years before present. Nature 453, 379-382 (2008).

57. Pertit, J. R. et al. Climate and atmospheric history of the past 420,000 years from the Vostok ice core, Antarctica. Nature 399, 429-436 (1999).

58. Hönisch, B., Hemming, N. G., Archer, D., Siddall, M. \& McManus, J. F. Atmospheric carbon dioxide concentration across the mid-Pleistocene transition. Science 324, 1551-1554 (2009).

59. EPICA Community Members. Eight glacial cycles from an Antarctic ice core. Nature 365, 143-147 (2004).

60. Schulz, M. \& Stattegger, K. Spectrum: spectral analysis of unevenly spaced palaeoclimatic time series. Comput. Geosci. 23, 929-945 (1997).

61. Torrence, C. \& Compo, G. P. A practical guide to wavelet analysis. Bull. Am. Meteorol. Soc. 79, 61-78 (1998).

62. Melice, J. L. \& Servain, J. The tropical Atlantic meridional SST gradient index and its relationship with the SOI, NAO and Southern Ocean. Clim. Dyn. 20, 447-464 (2003).

63. Singarayer, J. S. \& Valdes, P. J. High-latitude climate sensitivity to ice-sheet forcing over the last 120 kyr. Quat. Sci. Rev. 29, 43-55 (2010).

64. Gordon, C. et al. The simulation of SST, sea ice extents and ocean heat transports in a version of the Hadley Centre coupled model without flux adjustments. Clim. Dyn. 16, 147-168 (2000).

65. Li, Y., Lu, R. Y. \& Dong, B. W. The ENSO-Asian monsoon interaction in a coupled ocean-atmosphere GCM. J. Clim. 20, 5164-5177 (2007).

66. Lei, Y. H., Hoskins, B. \& Slingo, J. Natural variability of summer rainfall over China in HadCM3. Clim. Dyn. 42, 417-432 (2014).

\section{Acknowledgements}

Four anonymous reviewers are acknowledged for their valuable suggestions. We thank S. Spassov and H. Ao for discussing the paleomagnetic results; and L. He, F. Guo, Y. Yan, L. Ma, X. Liu, Y. Cao, X. Li, H. Wang and M. Zhao for field and laboratory assistants. This work was supported by grants from the Ministry of Science and Technology of China (No. 2016YFA0601902), the Chinese Academy of Sciences (No. 132B61KYSB20170005), the National Science Foundation of China (Nos. 41472163, 41525008, and 41572164), and the Fonds de la Recherche Scientifique-FNRS (grant MIS F.4529.18) to Q.Y. and M.C.

\section{Author contributions}

Y.S. and Z.A. designed the study and performed the fieldwork. Q.Y., M.C., P.A.-M. and A.B. conducted the sensitivity experiments and analyzed the modeling results. Y.S., L.L., H.C. and Y.L. participated in loess drilling and sampling. S.C. and W.L. contributed to carbonate isotope analysis. Z.A., X.Q., Q.L. and H.Z. analyzed the paleomagnetic data. L.Z., G.D., M.L. and W.Z. conducted the ${ }^{26} \mathrm{Al} /{ }^{10} \mathrm{Be}$ burial dating. All authors contributed to discussion, interpretation of the results, and writing of the manuscript. 


\section{Additional information}

Supplementary Information accompanies this paper at https://doi.org/10.1038/s41467018-08257-9.

Competing interests: The authors declare no competing interests.

Reprints and permission information is available online at http://npg.nature.com/ reprintsandpermissions/

Journal peer review information: Nature Communications thanks the anonymous reviewers for their contribution to the peer review of this work

Publisher's note: Springer Nature remains neutral with regard to jurisdictional claims in published maps and institutional affiliations. (c) (i) Open Access This article is licensed under a Creative Commons Attribution 4.0 International License, which permits use, sharing, adaptation, distribution and reproduction in any medium or format, as long as you give appropriate credit to the original author(s) and the source, provide a link to the Creative Commons license, and indicate if changes were made. The images or other third party material in this article are included in the article's Creative Commons license, unless indicated otherwise in a credit line to the material. If material is not included in the article's Creative Commons license and your intended use is not permitted by statutory regulation or exceeds the permitted use, you will need to obtain permission directly from the copyright holder. To view a copy of this license, visit http://creativecommons.org/ licenses/by/4.0/.

(C) The Author(s) 2019 